\title{
Concepções de estudantes de sétimo ano de uma escola de ensino fundamental sobre forma e função da flor em Boa Vista, Roraima
}

\author{
Claudete Cordeiro dos Anjos $^{1 *} \&$ Andréia Silva Flores ${ }^{2}$
}

1. Universidade Estadual de Roraima (UERR). Programa de Pós-graduação em Ensino de Ciências e Matemática (PPGEC). Campus Boa Vista, Programa de Pós-graduação em Ensino de Ciências, Rua Sete de Setembro 231, Canarinho CEP 69306-530, Boa Vista, RR, Brasil.

2. Instituto de Amparo a Ciência, Tecnologia e Inovação de Roraima (IACTI-RR), Herbário do Museu Integrado de de Roraima (MIRR), Av. Brigadeiro Eduardo Gomes 1128, CEP 69330-640, Boa Vista, RR, Brasil.

* Autor para contato: claudosanjos@gmail.com

Recebido em: 29 de setembro de 2016. Aceito em: 20 de novembro de 2016. Publicado PDF em: 24 de novembro de 2016

\section{RESUMO}

Concepções de estudantes de sétimo ano de uma escola de ensino fundamental sobre forma e função da flor em Boa Vista, Roraima. O ensino e aprendizagem de botânica tem sido alvo de inúmeras pesquisas as quais buscam elucidar a falta de interesse de estudantes e professores para esta área. A identificação dos conhecimentos prévios dos estudantes é importante, haja vista que o professor conhecendo o que o aprendiz já sabe sobre plantas poderá contribuir no desenvolvimento de estratégias para melhorar o ensino e, em decorrência, o aprendizado. Nesse contexto, este estudo teve como objetivo identificar as concepções prévias dos estudantes do sétimo ano do ensino fundamental no conteúdo morfologia floral. Para tanto, foi utilizado como instrumento de coleta de dados um questionário com perguntas abertas e fechadas sobre forma e função das flores. As informações obtidas foram analisadas qualitativamente e organizadas em categorias. A partir das informações obtidas foi possível observar que os estudantes entendem a flor como uma planta completa e em forma de margarida; a única estrutura floral que foi lembrada foi a pétala; alguma confusão quanto aos grupos de plantas que apresentam flores. Por outro lado, os estudantes apresentaram subsunçores quanto a função dos visitantes florais, reprodução e formação dos frutos.

PALAVRAS CHAVE: Ensino de botânica. Conhecimentos prévios. Morfologia floral.

\begin{abstract}
Conceptions of seventh grade students of a primary school about form and flower function in Boa Vista, Roraima State. The teaching and learning of botany has been the subject of numerous studies which seek to elucidate the lack of interest of students and teachers for this area. Studies show that teaching methods, the rich vocabulary in terms of Greek origin and Latin, as well as lack of contextualization, are factors that hinder the quality of teaching and learning. This study aims to identify prior knowledge of the students of the seventh grade of elementary school in floral morphology content. Thus, it was used as data collection instrument a questionnaire. The information obtained was analyzed qualitatively and organized into categories. With the data was observed that the students understand the flower as a complete plant and in the form of daisy. The only floral structure they know is the petal. They confuse flowering plants and plants without flowers, present subsumers as the function of floral visitors; reproduction and fruit formation.
\end{abstract}

KEY WORDS: Botany teaching. Previos knowledge. Flower morphology. 


\section{INTRODUÇÃO}

A aprendizagem significativa de conceitos botânicos pelos estudantes é motivo de preocupação para professores de ciências, biologia e pesquisadores da área, haja vista que esse campo (botânica) do conhecimento tem se mostrado por meio de pesquisas, que há um nível de desinteresse em estudar e também em ensinar botânica.

Embora seu objeto de estudo (plantas) exerça vasta influência na vida da humanidade desde sua origem, seja do ponto de vista alimentar, saúde, econômica, política e ambiental, dentre outros aspectos, a espécie humana, na sua maioria, ainda não se deu conta quão essenciais são as plantas para a manutenção da vida do planeta. Assim, conhecer esses seres não apenas do ponto de vista conceitual, como se trabalha nas escolas, mas em sua amplitude, o ensino e aprendizagem de botânica irão continuar subvalorizados.

Fazer uso de abordagens metodológicas que criem situações que estimulem e despertem o interesse em estudar botânica é uma necessidade que deve ser pensada pelos professores.

As plantas estão no nosso dia a dia. Essa é uma das razões que justificam a utilização dos conhecimentos espontâneos que os estudantes têm para iniciar a abordagem do assunto em sala de aula. Aprender significativamente é atribuir sentido ao que se estuda. $\mathrm{O}$ aprender tem significado quando o estudante consegue relacionar os novos materiais de aprendizagem com os com os conhecimentos específicos que ele já tem a respeito desses novos materiais.

Freitas et al. (2012), afirmam que o conhecimento é construído continuamente em decorrência das interações com o mundo físico e social, bem como das situações vivenciadas, não apenas as escolares, mas também as familiares e sociais. Além disso, consideram que os estudantes sempre têm algum tipo de informação sobre o que ele vê na escola (Freitas et al. 2012). A concepção dessas autoras sobre a importância dos conhecimentos prévios dos estudantes corrobora com as ideias da Teoria da Aprendizagem Significativa de Ausubel (TAS), na qual, os subsunçores são considerados recursos importantes na aprendizagem.

O levantamento dos conhecimentos prévios dos estudantes para o início do processo de aprendizagem é um dos pontos mais importante e defendido na teoria da aprendizagem significativa (TAS) de Ausubel (1980). Os conhecimentos prévios servem de esteio para os novos conceitos, contudo, estes têm que ser relacionáveis com o que vai ser estudado de modo não arbitrário e não literal (Ausubel et al. 1980). Assim, valorizar o que os estudantes trazem consigo à escola contribui na melhoria da aprendizagem.

A escola como espaço de discussão e difusão do conhecimento pode contribuir para favorecer nos estudantes o interesse em estudar, conhecer e mudar a concepção sobre as plantas. Para isso se faz necessário repensar o modo de ensinar botânica. Atualmente o ensino desse tema é desenvolvido em todos os níveis escolar onde pouco se discute a relação homem/ natureza.

É no sétimo ano do ensino fundamental que o conceito de flor e seus verticilos e função na reprodução das angiospermas são abordados. Por essa razão investigar o que os estudantes já sabem sobre esse conceito, ou seja, se os estudantes possuem subsunçores relacionáveis que apoiem os novos conceitos que serão introduzidos nessa série, é que se faz importante a realização de um diagnóstico inicial antes de adentrar nesse novo conceito. Identificar o que o aprendiz já sabe sobre um assunto que lhe vai ser ensinado e ensiná-lo a partir destes conhecimentos é o fator mais relevante que influencia a aprendizagem (Ausubel 2003).

Considerando a importância dos conhecimentos na construção da aprendizagem $\mathrm{e}$, das dificuldades que $\mathrm{o}$ ensino $\mathrm{e} a$ aprendizagem de botânica passam, esse estudo propôs-se a identificar os conhecimentos prévios sobre o assunto flor de estudantes de $7^{\circ}$ ano do ensino fundamental em uma escola pública em Boa Vista.

\section{MATERIAL E MÉTODOS}

Este trabalho teve enfoque qualitativo e é um estudo interpretativo e descritivo. Para a obtenção de dados foi utilizado um questionário no qual se buscou significados dos conceitos relacionados à flor (morfologia e função) pelos estudantes do $7^{\circ}$ ano do ensino fundamental de uma escola pública.

A pesquisa foi realizada em de junho de 2015 e para o seu desenvolvimento foram 
cumpridas formalidades éticas, tendo em vista que o estudo envolve seres humanos. A etapa de coleta de dados teve início após a permissão da escola, dos pais com a assinatura do termo de consentimento informado e dos estudantes envolvidos. Os mesmos foram informados de que a identificação e as informações coletadas seriam sigilosas e cada participante assinou um termo de assentimento.

As atividades foram realizadas em quatro etapas: 1) visitação à escola e apresentação da proposta do estudo à gestão, coordenação pedagógica e a professora de ciências; 2) reunião com os pais responsáveis pelos estudantes das turmas pesquisadas para apresentação do objetivo do estudo; 3) visitação as turmas dos sétimos anos para apresentar e informar aos estudantes como a pesquisa seria realizada e 4) aplicação dos questionários para obtenção dos dados.

Um questionário foi aplicado em duas turmas com um total de 47 estudantes. O questionário consistia de perguntas abertas e fechadas bem como a solicitação da elaboração de desenho relativo ao tema para o levantamento dos conhecimentos prévios sobre o assunto Morfologia floral. As perguntas do questionário iniciaram com a solicitação do Desenho de uma flor e a identificação de suas partes. Logo após foram elaboradas as seguintes questões: Todas as plantas possuem flores? Quais não apresentam? Você já observou alguns animais visitando as flores? Quais animais você observou? Por que estes animais visitam as flores? Como as plantas se reproduzem? Como surgem os frutos nas plantas? Você poderia explicar alguns modos como as plantas espalham suas sementes na natureza?

As respostas foram analisadas $\mathrm{e}$ organizadas em categorias, a partir de pontos em comuns entre elas.

\section{RESULTADOS E DISCUSSÃO}

Definir a flor não é tão simples, ainda mais quando se trata de nomenclaturas técnicas para estudantes do sétimo ano do ensino fundamental que ainda não tiveram contato com esse assunto em sala de aula. Embora seja uma estrutura vegetal bem comum, há uma distância entre $\mathrm{o}$ conhecimento formal (científico) e o empírico. Em função da sua relevância ecológica, social e afetiva o estudo da flor é necessário. Compreendê-la na sua complexidade demanda conhecimento.

O questionário pré-teste propôs-se a fornecer elementos sobre os conhecimentos prévios dos estudantes sobre $\mathrm{o}$ assunto morfologia floral e a função das flores. Neste estudo a investigação dos conhecimentos prévios dos estudantes sobre plantas foi realizada antes que o conteúdo fosse trabalhado em sala de aula. Este assunto só foi abordado após a finalização da pesquisa.

A primeira questão teve como objetivo identificar a percepção que os estudantes têm sobre a morfologia básica da flor. Para isso foi solicitado que desenhassem uma flor e em seguida identificassem suas partes.

Dos 47 estudantes participantes dessa fase, apenas três não responderam essa questão. Entre os 44 desenhos, três representaram uma flor isolada, ou seja, composta de estruturas semelhantes aos verticilos florais unidas em um eixo, que poderia corresponder ao pedicelo (Figura 1A, B).

Os demais, 41 estudantes a representaram como planta completa, isto é, com indicação de folhas, caule e raiz (Figura 2A, B, C e D). Um fato a ser destacado se refere ao formato como a flor foi representada, todos os desenhos lembram uma "margarida", apesar de haver uma diversidade de formas florais. Os desenhos são uma representação do que o indivíduo sabe a respeito do objeto, e não a realidade do que ele vê (Vygotsky 1989).

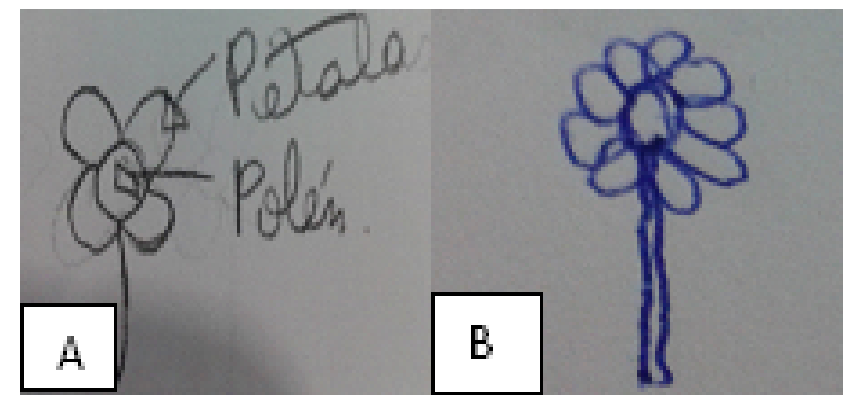

Figura 1. Representações de uma flor por estudantes. A. Representação da flor com apenas um verticilo floral (pétala) e referência ao pólen; B: representação de uma flor sem indicação de verticilos florais.

Após desenharem a flor foi solicitado que identificassem suas partes, a fim de identificar quais conhecimentos os estudantes tinham sobre os elementos florais. Ao analisar os desenhos foi constatado que o único elemento floral citado foi a pétala, a qual esteve presente nas respostas de 32 estudantes, seguido pelas 

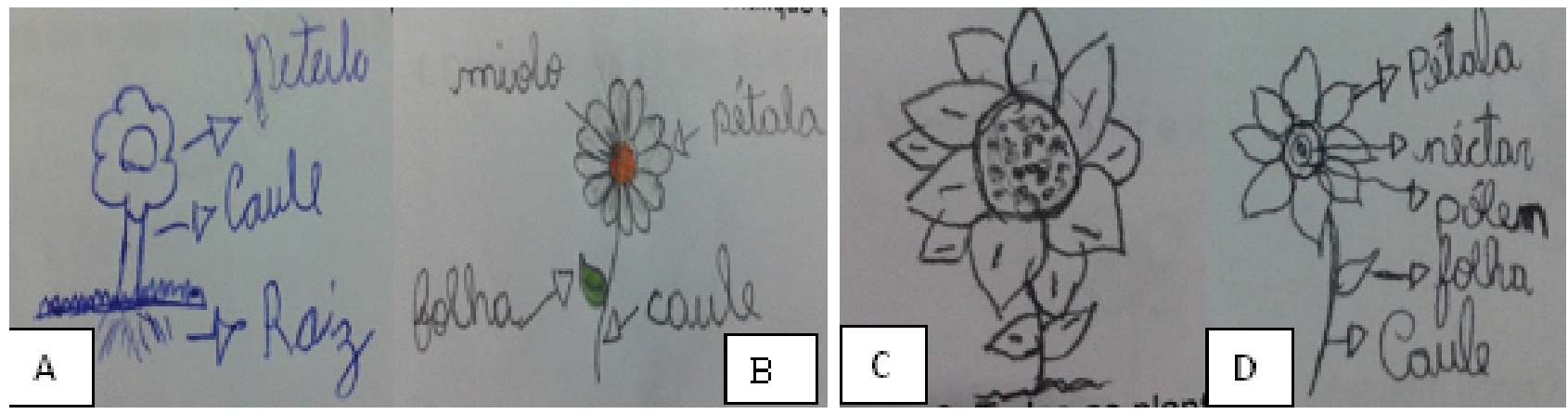

Figura 2. Ilustrações dos estudantes representando a flor como uma planta completa. A, B e D: Flor com identificação de estruturas florais, caule, folhas e raiz. C: flor sem identificação de estruturas.

expressões pólen e néctar que não são verticilos florais. $\mathrm{O}$ pólen foi mencionado por 13 estudantes, enquanto que o néctar foi citado por apenas três. O termo "miolo" também apareceu entre as citações, embora não faça parte do vocábulo científico, e sim da linguagem cotidiana. Assim, percebe-se que pétala é a estrutura floral mais familiar aos estudantes.

Ramos (2012), em uma pesquisa sobre o ensino de morfologia floral com estudantes do ensino médio, encontrou resultados semelhantes aos obtidos nesse estudo. Nos desenhos das flores foi citado o termo "miolo" para indicar a região central da flor. Nos dois trabalhos o termo miolo se refere a um círculo desenhado no centro da flor (Figura 2B). Outro dado em comum nos estudos refere-se ao termo pétala. Em ambos os estudos foi a peça floral mais citada pelos estudantes.

Observou-se que os estudantes apresentaram muitas dificuldades para nomear as partes da flor. No decorrer da realização da atividade, alguns disseram não saber os nomes das partes florais. $\mathrm{O}$ fato de não saberem ou não lembrarem os nomes tem como causas a pouca usualidade de termos científicos no cotidiano e ao fato de ainda não terem estudado o conteúdo no $7^{\circ}$ ano. Para Chassot (2000), o estudo das plantas é muito antigo, é um dos primeiros conhecimentos do homem. A necessidade em conhecer as plantas se deve a importância que esses seres têm na vida humana.

Os temas relacionados à botânica são geralmente apresentados de forma teórica e fragmentada, envolvendo muitas vezes a memorização de nomenclatura técnica e distante da realidade de professores e estudantes tornando-a desestimulante e subvalorizado no ensino de ciências (Faria et al. 2011; Kinoshita et al. 2006).
Essa problemática também é apontada por Krasilchik (2011, p.58), ao afirmar que "alunos não acompanham as aulas, porque são usadas palavras desconhecidas, ou porque eles atribuem aos termos significados diferentes dos atribuídos pelo professor". A mesma autora menciona também que o uso excessivo de termos técnicos pelo professor desenvolve no estudante a ideia de que biologia nada mais é que "um conjunto de nomes de plantas, animais, órgãos, tecidos e substâncias que devem ser memorizados (Krasilchik 2011, p.58)".

Em seguida, os estudantes foram questionados se as todas as plantas possuem flores. Deveriam responder sim ou não e em caso negativo, foi solicitado que respondessem quais não apresentam.

Nessa pergunta tivemos um total de 46 respondentes, destes, cinco responderam sim e 41 disseram não. Desse total respondido, 38 exemplificaram como plantas que não possuem flores: as samambaias (7), palmeiras (7), "ervas" (4), coqueiro (3), bambu (3), mamoeiro (3) e capim (3). As orquídeas, pitangueiras e cupuaçuzeiro também foram citadas por dois estudantes, já os gramados, plantas do campo, limoeiro, cactos, jambeiro e abacaxi foram citados por um estudante.

Além das Pteridófitas, as Briófitas e as Gimnospermas também não apresentam flores. Nos resultados foi verificado que somente sete participantes responderam "samambaias" enquanto que nenhuma outra planta das demais classes foi citada. Famílias botânicas pertencentes às Angiospermas como Arecaceae ("palmeiras" e "coqueiro" conforme citados pelos estudantes) são plantas que apresentam flores muito pequenas e cujo fruto é de grande tamanho e perduram por mais tempo na planta. Da mesma forma, as espécies de Poaceae 
("capim" e "bambu") apresentam flores inconspícuas e sem corola (ou esta é vestigial em alguns gêneros) e a maioria das espécies de bambu podem levar décadas para florescer. Nos dois últimos casos, observamos que a maioria das plantas citadas pelos participantes apresentam flores pouco vistosas (e alguns casos somente visíveis com lupa). Assim, esta pode ser uma das principais razões de serem mencionadas como plantas sem flores juntamente com as samambaias.

Ikemoto (2007) sugeriu atividades de campo como mecanismo de minimizar as dificuldades dos estudantes em botânica. Para a autora, essas atividades permitem o estudo das plantas como um todo, além de permitir que os estudantes percebam a interação desses seres com o ambiente. Ademais, as atividades de campo se forem desenvolvidas em ambientes propícios também favorecem a percepção da biodiversidade.

O passo seguinte foi responder se já haviam ou não observado animais visitando as flores e em caso afirmativo, apontar alguns animais observados e o porquê dessas visitas. Obtivemos 44 respostas positivas e duas negativas, ou seja, a maioria dos estudantes já observou animais visitando flores. Os animais mais vistos visitando as flores foram as abelhas (37) e os beija-flores (25). Outros animais também foram mencionados, dentre eles pássaros e borboletas (4), joaninha, formiga, mosca e besouro.

As abelhas são consideradas os principais visitantes florais e polinizadores efetivos das flores de muitas famílias de plantas (Souza \& Evangelista-Rodrigues 2007). As flores são verdadeiramente fontes em potencial de alimentos para as abelhas, de onde elas retiram o pólen e o néctar e, por outro lado a maioria das flores também depende desses animais para a polinização. Segundo Pinheiro et al (2015, p.184), "as abelhas dependem das flores (ou dos recursos florais) para sua sobrevivência, tendo dessa forma estabelecido relações estreitas com as angiospermas ao longo de sua evolução". Os beija-flores são também polinizadores, mas, de flores especializadas em forma de tubo. Os visitantes florais procuram basicamente por alimento e alguns poucos casos abrigo e local de reprodução (Machado \& Rocca 2010).

Para os participantes, essas visitas são para buscar alimentos (19), coletar pólen (14), coletar néctar (06), polinizar outras flores (05), elas virarem frutos (no caso, as flores) (01), retirar semente $(01)$ e misturarem o pólen com $o$ de outras plantas para elas fiquem mais bonitas (01). Observamos que $40 \%$ dos respondentes mencionaram que essas visitas têm como principal função a busca por alimentos e 45\% foram de respostas relacionadas (coletar pólen, néctar). Somente $15 \%$ das respostas relacionaram estas visitas aos aspectos de reprodução das plantas. Oliveira et al. (2009), em um estudo sobre reprodução das plantas com estudantes do $6^{\mathrm{a}}$ série do ensino fundamental encontrou resultados semelhantes a esse. A maioria dos estudantes relacionaram as visitantes florais à busca por alimento.

Nas respostas sobre formas de reprodução das plantas, pode-se observar que a polinização (14) e as sementes (12) foram as respostas que mais se repetiram, seguidas por forma assexuada (06), pela fotossíntese (05), frutos caem no solo (01) e pelo caule (01). Percebe-se que há uma visão limitada no significado de termos como "polinização" e "reprodução". Nas angiospermas a polinização é o processo de transporte do grão de pólen de uma flor para outra flor (podendo ocorrer no mesmo indivíduo ou entre indivíduos diferentes). Reprodução pode ocorrer de forma sexuada ou assexuada (em algumas plantas ainda podem estar envolvidos vários outros processos mais complexos). A reprodução sexuada envolve a presença de gametas femininos e masculinos, enquanto que na assexuada envolve divisão de tecidos somáticos, ou seja, tecidos vegetativos e esporos. Na reprodução sexuada para que esta seja efetivada deve ocorrer a fecundação, quando o gameta se une ao outro para a formação do zigoto (embrião).

Ao analisar as respostas, observou-se que os estudantes não relacionaram as estruturas florais envolvidas na reprodução. Esta observação também foi feita por Oliveira et al. (2009) ao questionar estudantes sobre reprodução das plantas. Em sua pesquisa a maioria dos estudantes menciona as sementes como estruturas responsáveis pela reprodução.

A penúltima questão teve como objetivo avaliar o que os estudantes têm como subsunçores sobre a formação dos frutos. Ao analisarmos as explicações, cerca de $50 \%$ dos estudantes responderam que os frutos são originários a partir das flores (28) ou da reprodução (03). Outros estudantes responderam que os frutos surgem da 
fotossíntese (03); das folhas (02); do pólen (02); da glicose que há nas árvores (01); surgem à medida que as arvores crescem (01). Embora os resultados apontem a flor como principal responsável pela formação dos frutos, os participantes não mencionam estruturas como ovário e estames. Isto era esperado, uma vez que os participantes não indicaram estas estruturas no desenho da flor solicitado na primeira pergunta do questionário.

Por último, foi solicitado que explicassem como as plantas espalham suas sementes na natureza. Segundo os dados obtidos, as sementes são espalhadas pelos animais (30); pelo vento (07) e pelos próprios frutos que liberam suas sementes (06). Quatro (04) participantes não souberam responder. Pelas respostas pode-se observar que os participantes já têm conhecimentos sobre a disseminação das sementes (Quadro 01). estruturas especializadas das plantas para esta função.

Por outro lado, os participantes encontraram dificuldades principalmente na nomenclatura das partes da flor, bem como na delimitação das mesmas quanto sua estrutura e na definição dos significados dos termos "polinização", "reprodução" e "fecundação". Além destas também verificamos a necessidade de ampliar o conhecimento dos participantes sobre a formação dos frutos a partir das estruturas florais e a diversificação de estruturas nos frutos e sementes para a dispersão dos mesmos.

A concepção de flor, seus verticilos, sua relação com a reprodução e seus aspectos ecológicos, econômicos e sociais e até afetivos não são temas de discussão no cotidiano. Essa discussão é necessária, já que as flores são importantes para inúmeras espécies animais

Quadro 1. Respostas dos estudantes do $7^{\circ}$ ano do ensino fundamental de uma escola pública de Boa Vista, Roraima para a pergunta 07 do questionário pré-teste.

\begin{tabular}{|l|}
\hline Questão 7: Você poderia explicar alguns modos de como as plantas espalham suas sementes na natureza? \\
\hline Respostas \\
\hline "Geralmente as sementes se espalham com o vento". \\
\hline "Por meio dos pássaros, beija-flor e outros animais". \\
\hline "Pelos morcegos, eles se alimentam e cospem a semente". \\
\hline "Através dos frutos, que são jogados as vezes, pelos seres humanos" \\
\hline "Muitas vezes com os pássaros que escondem suas sementes na terra e acabam esquecendo, então cria uma nova planta". \\
\hline "Quando os frutos caem no chão ou outros animais pegam as frutas e jogam as sementes fora". \\
\hline "Os animais comem as plantas a maioria das vezes eles jogam as sementes na natureza". \\
\hline "Quando uma fruta cai e fica apenas a semente. Após um tempo ela automaticamente fica enterrada". \\
\hline
\end{tabular}

A partir das respostas se percebeu que os estudantes reconhecem a importância de animais como os morcegos e pássaros para a dispersão das sementes, bem como do vento e do ser humano para a ocorrência desse processo.

Os estudantes participantes apresentaram conhecimentos prévios sobre aspectos ecológicos da flor relacionados a sua associação com a fauna, ou seja, relacionaram os animais e o objetivo destas visitas à flor. Bem como um conhecimento mais inclusivo sobre os agentes dispersores das sementes, embora não tenha sido questionado a função da dispersão para a conservação das espécies e inclusive o homem que dependem dos produtos oriundos dessa estrutura, tais como frutos, sementes e "delas depende a perpetuação da espécie vegetal (Souza et al 2013, p. 188)", bem como pólen e néctar. Levar essa discussão para a sala de aula é relevante para que o estudante se aproprie desses conceitos para compreender a importância das flores na manutenção da vida vegetal e animal do planeta. Quando esta discussão acontece a partir do que o estudante já sabe, a possibilidade de ocorrer uma aprendizagem mais significativa é mais provável. Ensinar um novo conceito a partir do que o estudante já sabe é importante para dar novo sentido ao 
sabe é importante para dar novo sentido ao conceito antigo e, dar significado ao novo conceito (Moreira 2012).

Um engano comum que o professor empreende é iniciar um novo conteúdo sem antes diagnosticar o que os estudantes têm de significativo na estrutura cognitiva que sirvam de âncora para associarem ao novo conceito a ser introduzido. Para Viola (2011, p. 84), “os educadores não devem tomar como adquirido o conhecimento que seria de esperar que os educandos tivessem em determinado nível de escolaridade". Não considerar a possibilidade de os estudantes não terem conhecimentos prévios sobre determinado assunto pode acarretar prejuízos no processo e ensino e aprendizagem.

O ensino de Ciências e Biologia deve primar por uma aprendizagem focada na motivação, interesse e contextualização com a realidade do estudante. Estudos como o de Melo et al. (2012), indicam que os procedimentos metodológicos nessa área de ensino devem ser revistos e que há necessidade de se buscar estratégias a fim de tornar o ensino mais prazeroso.

Caso os procedimentos e estratégias metodológicas não se renovem para atender a demanda atual, o ensino de Botânica tende a manter-se imbuído de memorização, aversão, desinteresse e, sobretudo a falta de percepção das importantes e existentes relações entre seres humanos e plantas que não são percebidas na maioria das vezes pelos estudantes da educação básica (ensino fundamental e médio). $\mathrm{O}$ professor deve promover um ensino dinâmico, problematizador e instigante ao aprendiz, permitindo-o a sair da sua zona de conforto que o mantém passivo diante das realidades social e cultural.

\section{CONSIDERAÇÕES FINAIS}

O ensino de botânica é impregnado de práticas enfadonhas e que de longe relacionam as plantas ao sujeito da aprendizagem. Ensinase os diferentes grupos vegetais, classificação, morfologia, fisiologia, dentre outros aspectos sem considerar o contexto do estudante e os conhecimentos que vêm arraigados na sua essência. É como se as plantas fossem seres desconhecidos. É comum o professor iniciar a abordagem sobre $\mathrm{o}$ assunto sem antes diagnosticar os conhecimentos que os estudantes têm sobre o assunto. Embora haja relação muito próxima entre os humanos e as plantas, no momento de ensinar isso geralmente não é considerado.

O estudante quando chega à escola traz consigo uma série de conhecimentos e experiências que devem ser utilizados e respeitados pelo professor. Nenhum estudante chega vazio de conhecimento. E, aproveitar essas experiências e conhecimentos é uma forma de valorizar o estudante. Identificar a presença de subsunçores é uma medida importante para qualquer intenção de ensino de um novo conceito. Quando novos conceitos e conceitos pré-existentes na estrutura cognitiva do estudante são relacionáveis, há formação de novos sentidos e também de significados. Lançar mão de recursos didáticos que facilitem a introdução desses novos conceitos e que facilitem a abordagem e despertem o interesse e motivação nos estudantes, é essencial para a ocorrência de aprendizagem significativa.

Ao analisar esse estudo, identifica-se a presença de muitos conceitos sobre o assunto aqui tratado - Botânica, embora tenha sido abordado muito superficialmente durante a trajetória escolar dos participantes dessa pesquisa. Esse resultado se mostra importante para que os professores pensem sua prática focada na aprendizagem do estudante e que os conhecimentos que eles têm devem ser a base para a aquisição de novos conceitos.

\section{REFERÊNCIAS BIBLIOGRÁFICAS}

Ausubel, D. P., Novak, J. D. \& Hanesian, H. 1980. Psicologia Educacional. Rio de Janeiro: Interamericana.

Ausubel, D. P. 2003. Aquisição e Retenção de Conhecimentos: Uma Perspectiva Cognitiva. Plátano Edições Técnicas.

Chassot, A. 2000. Alfabetização Cientifica: questões e desafios para a educação. Ijuí: editora Unijuí.

Faria, R.L., Jacobucci, D.F.C. \& Oliveira, R.C. 2011. Possibilidades de ensino de botânica em um espaço não-formal de educação na percepção de professoras de ciências. Ensaio: Pesquisa em Educação em Ciências 13(1): 87103.

Krasilchick, M. 2011. Prática de Ensino de biologia. 4. ed. 3 Reimp. São Paulo: Edusp.

Ikemoto, E. 2007. Espécies arbóreas, arbustivas e 
herbáceas do Parque Taquaral (Campinas, SP) - Subsidios para atividades de ensino de não formal de botânica. 280 f. Dissertação (Mestrado). Universidade Estadual de Campinas, Instituto de Biologia. São Paulo.

Kinoshita, L.S. et al. 2006. A Botânica no Ensino Básico: relatos de uma experiência transformadora. São Paulo: Rima.

Machado, C. G. \& Rocca, M. A. 2010. Protocolos para o estudo de polinização por aves. In: Accord, I., Straube, F. C. \& Von Matter, S. (Org.). Ornitologia e conservação: ciência aplicada, técnicas de pesquisa e levantamento. Rio de Janeiro: Technical Books, p. 471-490.

Melo, E. A., Abreu, F.F., Andrade, A.B. \& Araújo, M.I.O. 2012. A aprendizagem de botânica no ensino fundamental: dificuldades e desafios. Scientia Plena 8(10):1-8.

Moreira, M.A. 2012. ?Al final, qué es Aprendizaje Significativo? Revista Qurriculum 25: 29-56.

Oliveira, A. L. de. et al. 2009. Reprodução das plantas: conhecer as idéias dos alunos e trabalhar a partir e com elas em situações de ensino, aprendizagem e avaliação. In. VII Encontro Nacional de Pesquisa em Educação em Ciências - VIIEnpec. Florianópolis.

Pinheiro, M. et al. 2015. Polinização por abelhas. In: Rech, A., Agostini, K., Machado, I.C.S. \& Oliveira, P.E.A.M.. (Org.). Biologia da Polinização. 1 ed. Editora Projeto Cultural 1: 205-233.

Ramos, F. Z. 2012. Limitações e contribuições da mediação de conceitos de botânica no contexto escolar. 145 f. Dissertação (Mestrado). Centro de Ciências Exatas e Tecnologia, Fundação Universidade Federal de Mato Grosso do Sul, Campo Grande - Mato Grosso do Sul.

Souza, D. L. \& Evangelista-Rodrigues, A. 2007. As Abelhas Como Agentes Polinizadores. REDVET. Revista Electrónica de Veterinária. Vol. III, Número 3. Disponível em: http:// www.veterinaria.org/revistas/redvet/

n030307/030710.pdf. Acesso em: 03 de abril de 2016.

Souza, V.C., Flores, T.B. \& Lorenzi, H. 2013. Introdução à Botânica. Morfologia. Instituto Plantarum, São Paulo.

Viola, M. G. 2011. Estudo sobre a concepção de flor para educandos de uma escola estadual de educação básica em Porto Alegre, RS. Dissertação (Mestrado), Instituto de Ciências Básicas da Saúde, Universidade Federal do Rio Grande do Sul - UFRGS, Porto Alegre - Rio Grande do Sul, $111 \mathrm{f}$.

Vygotsky, L. S. 1989. Formação social da mente.
3. ed., São Paulo: Martins Fontes. 